\title{
Nutritional status and associated factors among elderly people in primary care center
}

\author{
Maturos Na Badalung Kanin ${ }^{1}$, Bosittipichet Tatree ${ }^{1}$ and Leesri Thanakamon ${ }^{2, *}$ \\ ${ }^{1}$ Department of Social Medicine, Phra Nakhon Si Ayutthaya Hospital 46/1 U-Thong Rd. Pratoochai sub-district Phra \\ Nakhon Si Ayutthaya district Phra Nakhon Si Ayutthaya 13000 Thailand. \\ 2 Department of Community Health Nursing, Institute of Nursing, Suranaree University of Technology 111 University \\ Avenue Suranaree Subdistrict, Muang Nakornratchasima 30000, Thailand.
}

Publication history: Received on 01 March 2020; revised on 06 March 2020; accepted on 09 March 202

Article DOI: https://doi.org/10.30574/gscarr.2020.2.3.0018

\begin{abstract}
Nowadays, Thailand is entering an aging society. There are many health problems of the elderly. One of the important problems is the problems from the deterioration of the body related to nutritional status. This study is aimed to explore nutritional status and the prevalence of malnutrition including related factors among the elderly in Primary Care Center. The subjects in this study are 250 elderly people living in the area of responsibility of Wat Phraya Tikaram Primary Care Center, selected by simple random sampling. The data are collected by interviewing the sample groups in the community. From December 2019 to January 2020 by using the Mini nutritional assessment ${ }^{\circledR}$. The data were analyzed using descriptive statistics and multiple regression analysis by stepwise method. In totally 250 elderly people, 104 people are at risk of malnutrition or equal to $41.6 \%$ and 26 people, equal to $10.4 \%$, are classified as malnutrition. Exercise, activities of daily living, body mass index, underlying disease, age and the presence of residents are the significant factor related to malnutrition among the elderly.
\end{abstract}

Keywords: Nutritional status; Malnutrition; Elderly; Primary Care Center

\section{Introduction}

In 2017 , there were $17 \%$ or around 11 million elderly residents who aged 60 years old and above out of all 65.5 million residents in Thailand. It is predicted that by the next four years, Thailand will become an aging society as the proportion of residents aged 60 years old or higher is projected to increase to $20 \%$ [1]. Regarding to the community of Wat Phrayattikaram, located in Pailing Sub-district, Muang District, Phra Nakhon Si Ayutthaya Province, there are 1,375 elderly residents, accounted for $16 \%$, of all 8,490 residents. Of all residents, these senior residents were reported to have the most frequent rate in receiving medical service as well as the largest healthcare expenditures [2]. Therefore, it can be concluded that the methods of promoting health, preventing diseases, providing treatments, recovering and improving medical service for aged residents are greatly crucial in preparing for the upcoming aging society.

Nutritional status is one of important health criteria for elderly people. Normal nutritional status indicates that people have a sufficient level of nutrients that their bodies require and an ability to absorb nutrients efficiently. Currently, an increasing number of elderly people suffer from malnutrition since the rise in age leads to several contributing factors, including a lack of appetite in food, dental caries, nerve degeneration, gastrointestinal diseases, decreasing absorptive abilities and bowel-related issues. These symptoms make it very challenging for elderly to eat regularly and enjoy the taste of their meals, so this results in their higher risk of having malnutrition than their younger counterparts [3].

\footnotetext{
${ }^{*}$ Corresponding author: Leesri Thanakamon
} 
Malnutrition in elderly leads to falls and fractures due to decreased bone mass [4], and it also causes a weak immune system and a decline in cognitive functions. It is found that elderly with malnutrition are more likely to be admitted in hospitals than those who do not suffer from this disease [5]. Therefore, assessing and examining elderly's nutritional status is essential as it will assist in detecting malnutrition in elderly so that the treatments will be provided to mitigate their disease promptly [6].

The options in evaluating and examining nutritional status are various as each assessment is different in speeds and specifics. However, MNA ${ }^{\circledR}$ assessment is widely acclaimed for its rapidness and credibility in evaluating elderly's nutritional status both in community and medical center [7]. It is also an effective tool which can be used to determine and divide elderly into two groups: those who are at risk of having malnutrition and those who have a clear symptom of having malnutrition [8]. The researcher, hence, decides to choose MNA ${ }^{\circledR}$ assessment in this study to assess nutritional status and to study factors contributing to malnutrition of elderly residents living in the community of Wat Phrayattikaram. Since the assessment of nutritional status had never been done in this are before, so studying the disease prevalence and its contributing factors will benefit residents in this area by providing better methods in the prevention of malnutrition in elderly.

\section{Research Methodology}

\subsection{Objective}

- To study nutritional status and the prevalence of malnutrition of elderly residents, living in the community of Wat Phrayattikaram, located in Muang District, Phra Nakhon Si Ayutthaya Province, Thailand.

- To analyze factors affecting malnutrition in elderly residents, living in the area under administration of Wat Phrayattikaram Primary Care Center, Thailand.

\subsection{Research Design and Processes}

This is a cross sectional study. Samples are collected from the elderly population, living in the area under administration of Wat Phrayattikaram Promoting Health Hospital, located in in Pailing Sub-district, Muang District, Phra Nakhon Si Ayutthaya Province. The data is collected through doing a survey in the community between December 2019 and January 2020. Simple random sampling is used in this study, and there are 250 samples.

Inclusion criteria are that 1) the samples must be 60 years old or older residents living in the community of Wat Phrayattikaram or in Moo 2, 5 or 6, located in Pailing Sub-district, Muang District, Phra Nakhon Si Ayutthaya Province and 2) they must be able to communicate and understand Thai language. There are no exclusion criteria in this study.

The researcher uses Mini Nutritional Assessment (MNA) and a questionnaire, inquiring about personal data such as age, weight, height, smoking and drinking habits, and so on, in collecting data from the sample group. The participants have the opportunity to ask the researcher questions should they wish.

The data is analyzed by a computer program into descriptive statistics, such as percentage, average number and standard deviation. Statistics from multiple regression analysis, using a stepwise approach, is applied to present general data of samples and analyze factors contributing to elderly's malnutrition, and the level of statistical significance is at $0.05(\mathrm{p}<0.001)$.

\subsection{Right to Protection and Research Ethics}

This study has been approved by the committee of research ethics regarding to human study of Phra Nakhon Si Ayutthaya Hospital, Thailand. (The number of project: 023/62 signed at December 18, 2019). 


\section{Results}

Table 1 General Information and Health Information of Elderly People $(n=250)$

\begin{tabular}{lll}
\hline & Number & Percentage \\
\hline Sex & 72 & \\
Male & 178 & 28.8 \\
$\quad$ Female & & 71.2 \\
Age (year) (mean \pm SD 69.84 & & \\
$60-69$ & $1539)$ & 61.2 \\
$70-79$ & 59 & 23.6 \\
$>80$ & 38 & 15.2
\end{tabular}

BMI (kg. $\left./ \mathrm{m}^{2}\right)($ mean \pm SD $24.57 \pm 4.14)$

$\begin{array}{lll}\text { Below baseline } & 17 & 6.8 \\ \text { Normal } & 123 & 49.2 \\ \text { Upper baseline } & 88 & 35.2 \\ \text { Obesity } & 22 & 8.8\end{array}$

Status

$\begin{array}{lll}\text { Single } & 38 & 15.2 \\ \text { Married } & 212 & 84.8\end{array}$

Education

$<$ Primary School

80.4

$>$ Primary School

Income

None

$>$ 3,000 Baht/Month

Money Status

Not Enough

Sufficiency

Underlying Disease

Hypertension

Hyperlipidemia

Diabetes

Chronic Kidney Disease

Bed Ridden

Heart Disease

Cerebrovascular disease

Daily Activities

Need support

69

181

Active

9

150

60.0

100

40.0

150

60.0

100

40.0

219

87.6

167

66.8

107

42.8

88

35.2

9

3.6

6

2.4

7

2.8

5

2.0

27.6

72.4 


\begin{tabular}{lll}
\hline & Number & Percentage \\
\hline Smoking & & \\
Yes & 12 & 4.8 \\
No & 238 & 95.2 \\
Alcohol consumption & & \\
$\quad$ Yes & 35 & 14.0 \\
No & 215 & 86.0 \\
Exercise & & \\
Yes & 184 & 73.6 \\
No & 66 & 26.4 \\
Related People in Family & & \\
Yes & 223 & 89.3 \\
Alone & 27 & 10.8 \\
\hline
\end{tabular}

According to the first table, it illustrates general and health information of 250 samples. The majority of samples are females, accounting for 178 samples (71.2\%). Regarding to age, 153 samples (61.2\%) are between 60 and 69 years old, and the average age is $69.84 \pm 8.39$ years old. 123 samples (49.2\%) have normal Body Mass Index (BMI), and the average BMI is $24.57 \pm 4.14 \mathrm{~kg} / \mathrm{m}^{2}$. There are 212 married samples $(84.8 \%)$. Most of the samples' education, or 201 samples $(80.4 \%)$, is lower than high-school degree. It is found that 150 samples $(60.0 \%)$ do not make money for a living, and 150 samples (60.0\%) report that they do not have financial savings. 219 samples $(87.6 \%)$ report that they have chronic diseases. 167 of them (66.8\%) have high blood pressure while 107 (42.8\%) and 88 (35.2\%) of them have dyslipidemia and diabetes respectively. 181 samples $(72.4 \%)$ report that they do not require special assistance in performing their daily routines. 238 samples (95.2\%) report that they do not smoke, and 215 samples (86.0\%) state that they do not drink alcohols. 184 samples (73.6\%) report that they do some exercises. Lastly, 223 samples (89.3\%) state they live in multi-person households.

Table 2 Nutritional Status of Elderly evaluated by Mini Nutritional Assessment (MNA)

\begin{tabular}{lll}
\hline & Number & Percentage \\
\hline Normal & 120 & 48.0 \\
Risks & 104 & 41.6 \\
Malnutrition & 26 & 10.4 \\
\hline
\end{tabular}

The second table indicates nutritional status of the elderly residents, evaluated by Mini Nutritional Assessment (MNA). It is found that most samples, 120 of all samples (48.0\%), have normal nutritional status. This is followed by those who are at risk of having malnutrition and those who suffer from malnutrition, accounting for 104 samples (41.6\%) and 26 samples $(10.4 \%)$ respectively. The average score is at $22.66 \pm 4.14$.

Table 3 The Relation between predictive factors and malnutrition among elderly people

\begin{tabular}{llllll}
\hline Model & Sum of squares & df & Mean Square & F & p-value \\
\hline Regression & 1311.974 & 6 & 218.662 & 17.932 & $<0.001^{*}$ \\
Residual & 2963.126 & 243 & 12.194 & & \\
Total & 4275.100 & 249 & & & \\
\hline
\end{tabular}


Regarding to the analysis of factors contributing to malnutrition of elderly living in the community of Wat Phrayattikaram, Phra Nakhon Si Ayutthaya Province, it is processed by multiple regression analysis with a stepwise method. In this study, predictor variables include gender, age, Body Mass Index (BMI), marriage status, education level, income, financial status, chronic diseases, daily habits, smoking and drinking habits, regularity of exercise, and having a multi-person household. From the analysis it is found that there are six steps, and in the results of this study, it will illustrate only the analysis of the sixth step, the last step which is analyzed by a stepwise approach.

Table 4 The Relationship of Predictive Factors and Malnutrition among Elderly people

\begin{tabular}{|c|c|c|c|c|c|}
\hline Model & Unstandardized B & Coefficients SE & $\begin{array}{l}\text { Standardized } \\
\text { coefficients Beta }\end{array}$ & $\mathbf{t}$ & p-value \\
\hline Constant & 19.284 & 2.705 & & 7.130 & $<0.001^{*}$ \\
\hline Active Ageing (ADL) & 2.149 & .521 & .232 & 4.126 & $<0.001^{*}$ \\
\hline Exercise & 2.261 & .520 & .241 & 4.348 & $<0.001^{*}$ \\
\hline Body Mass Index (BMI) & .221 & .055 & .221 & 3.979 & $<0.001^{*}$ \\
\hline Underlying Disease (UD) & -2.028 & .689 & -.162 & -2.945 & $0.004^{*}$ \\
\hline Age & -.069 & .028 & -.140 & -2.446 & $0.015^{*}$ \\
\hline Related People & 1.515 & .716 & .114 & 2.114 & $0.036^{*}$ \\
\hline
\end{tabular}

The fourth table represents multiple regression analysis between predictor variables and the final step (the sixth step) of malnutrition. It is found that not requiring special assistance, exercising, BMI, having chronic diseases and having a multi-person household are predictor factors contributing to malnutrition in elderly residents living in the community of Wat Phrayattikaram (the level of statistical significance is at $\mathrm{p}<0.05$ ). Exercising is the main factor most responsible for malnutrition in the elderly residents (standardized regression coefficient ( $\beta$ ) is 0.241 ). This is followed by not requiring special assistance on regular basis, BMI, having chronic diseases, age and having a multi-person household, which their standardized regression coefficient $(\beta)$ are $0.232,0.221,-0.162,-0.140$ and 0.114 respectively. Exercising, not requiring special assistance on regular basis, BMI, and having a multi-person household are positive correlation with malnutrition in elderly residents, while having chronic diseases and age are negative correlation with malnutrition in elderly. These six predictor factors have correlation coefficient at 0.554 and statistical significance at $0.05(\mathrm{p}=0.036)$. It can be used to predict the occurrence of malnutrition at $30.7 \%$, and prediction error is at \pm 3.49 . On the other hand, gender, marriage status, education level, income, financial status and smoking and drinking habits do not statistically have an influence on the occurrence of malnutrition in elderly residents living in the community of Wat Phrayattikaram, Phra Nakhon Si Ayutthaya Province, Thailand.

\section{Discussion}

From the analysis of the study, it is found that exercising is a factor having positive correlation with malnutrition ( $p$ value $<0.001$ ). It is found that there are 184 elderly residents in the community of Wat Phrayattikaram who exercise, and this accounts for $73.6 \%$ of all participants. According to the study by Aritsara Sookwatjanee, Exercise is a health promoting activity which can strengthen a functioning ability of muscles and joints, and it can raise the life quality of elderly [9]. These benefits are an important factor that could lead elderly to have good nutritional status. In researcher's opinion, exercise is an activity that requires a great proportion of physical effort, so a person who can exercise must be the one who can perform daily routines, such as walking and eating, by themselves. Additionally, those who exercise regularly tend to be the ones who pay attention on taking care of their health better than those who never exercise. Therefore, this makes exercising to be one of the most important factors that having positive correlation with malnutrition. This corresponds with the results of the study that elderly's ability in performing daily routine has positive correlation with malnutrition, and it is found that not requiring special assistance on regular basis has positive correlation with malnutrition (p-value<0.001). There were 181 participants who state that they do not require special assistance in performing daily routine, and this makes up for $72.4 \%$ of all participants. This corresponds with the study of Nielson et al. [10] as they found that elderly people who have difficulties in performing their daily routines, especially regarding to eating [11], are prone to have malnutrition than other people with the same age. The results of this study correspond with other studies from many parts of the world [12]. 
Body Mass Index (BMI) is a popular indicator used to assess individual's nutritional status [13]. In this study, it is found that BMI has a positive correlation with malnutrition (p-value<0.001). In the study of Julai Luzzi Valmórbida et al. [14], it is reported that people with healthy BMI range is correlated with their better understanding and awareness of nutritional status than those with unhealthy BMI range. As a result, they can manage their nutritional status better and more properly. Likewise, the study of Dana L. Craven et al. [15] and other studies also provide the similar results [16]. Regarding to chronic diseases, if elderly have suffered from chronic diseases for a long time or they have different chronic diseases, this might link to the occurence of malnutrition $[17,18]$. From the results of study, it is found that having chronic diseases has a negative correlation with malnutrition $(p$-value $=0.004)$. It is found that of all participants, 219 of them have chronic diseases, accounting for 87.6\%. This corresponds with the study of Damião [19], which indicates that elderly who have chronic diseases, especially respiratory diseases and chronic kidney disease (CKD), are more likely to suffer from malnutrition than their counterparts who are at the same age. Having chronic diseases requires a patient to eat selectively in order to prevent complications, and a patient is also required to change their daily habits to lead a healthier life. If the elderly go on diet with a lack of understanding of nutritional status, they are prone to suffer from malnutrition. However, if the elderly with chronic diseases do not have proper diet, this may lead to complications which can lead to illnesses and malnutrition as well [20].

An increase in age is another important factor contributing to malnutrition. From the results of this study, it is found that an increase in age has a negative correlation with malnutrition ( $p$-value $=0.015$ ). This corresponds with the studies from several countries [21,22]. An increase in age leads to the degeneration of many organs, a lack of appetite in food, and a decline in abilities regarding to smell and taste, so this causes the elderly to be able to have a considerably smaller portion of food. Furthermore, the slower movement along digestive tracts and the decline in acid secretion in the stomach could results in consuming less food [23] which eventually leads to malnutrition as well.

SOLGER (2010) study aims to study about the correlation between elderly's single-person households and malnutrition with the elderly living in Mediterranean countries, and it is found that there is no correlation between these two factors. However, this does not correspond with the results of this study as it is found that having a multi-person household has a positive correlation with malnutrition ( $p$-value $=0.036$ ). This might be because financial and social conditions are different in each geographic context, and the differences that result in dissimilar results of studies may include the way members living together, elderly's social welfare provided by governments and so on.

\section{Conclusion}

Malnutrition is one of serious issues for many elderlies as it can lead them to several health problems, and it can decrease their life quality. The results of the study can be applied to improve a plan in how to handle the issue of malnutrition in elderly living in the community of Wat Phrayattikaram. The plan should include informing elderly about the basis of nutrients and self-healthcare so that they can maintain their life quality as well as possible. This can also assist in dealing with changes caused by the upcoming aging society in Thailand.

In researcher's perspective, collecting data from different areas will help the collectors to have a clearer vision of malnutrition in their area since the issue of malnutrition can be different in each area caused by different factors such as geographic factor, social and financial factors and so on. Therefore, to reach the highest efficiency in mitigating the issue, it requires more specific solutions.

\section{Compliance with ethical standards}

\section{Acknowledgments}

I would like to express my sincere gratitude to public health officers at Wat Phrayattikaram Primary care unit for their support in data collection and to professors at Family Practice of Phra Nakhon Si Ayutthaya for their advises throughout the process of this study.

\section{Disclosure of conflict of interest}

The authors declared no potential conflicts of interest with respect to the research, authorship, and or publication of this article. 


\section{Statement of ethical approval}

As this study involves human subject, it has been approved by the committee of research ethics regarding to human study of Phra Nakhon Si Ayutthaya Hospital, Thailand. (The number of project: 023/62 signed at December 18, 2019).

\section{Statement of informed consent}

This study involves information about any individual such as survey, interview. The informed consent was obtained from all individual participants included in the study."

\section{References}

[1] Pramote Prasatkul. (2017). Situation of Elderly people in Thailand. Bangkok: Dauntula publishing.

[2] Health Insurance Research Office. (2012). Social and Health Institute. Performance of Health Care for Elderly and impact on Public Health Care Financing during 2011-2022 [Internet].

[3] Department of Medical Services, Ministry of Public Health, Institute Of Geriatric Medicine. Integrated Care for Elderly People (Revised Version). Bangkok.

[4] War Veterans Organization of Thailand Publishing. (2010).

[5] Westergren A, Hagell P and Sjödahl Hammarlund C. (2014). Malnutrition and risk of falling among elderly without home-help service - A cross sectional study. J Nutr Heal Aging, 18(10), 905-11.

[6] The Institute Of Geriatric Medicine. Department of Medical Services, Ministry of Public Health, Thailand. Guidelines for Elderly Care (Geriatric syndromes). Bangkok: Is August Company, (2015).

[7] Skates JJ and Anthony PS. (2012). Identifying Geriatric Malnutrition in Nursing Practice: The Mini Nutritional Assessment (MNA®) -An Evidence-Based Screening Tool. J Gerontol Nurs [Internet]. Mar [cited 2019 Jul 30], 38(3), 18-27.

[8] Vellas B, Guigoz Y, Garry PJ, Nourhashemi F, Bennahum D, Lauque S, et al. (1999). The mini nutritional assessment (MNA) and its use in grading the nutritional state of elderly patients. Nutrition [Internet]. Feb [cited 2019 Jul 31], 15(2), 116-22.

[9] Kittikorn Nilmanat, Kanittha Naka, Wipawee Kong-in, Aim-on Sai-jew, Pachariya Chailungka and Piyaporn Boonphadh. (2013). Nutritional Conditions of Elderly People in the Three Southernmost Border Provinces Thai Journal of Nursing Council, Vol. 28 No.1, 75-84.

[10] Arisa Suwatjanee. (2013). Exercise in Elderly People. Journal of Srinakarintawirot Research and Development, $4(8), 216-223$.

[11] Nielsen MM, Maribo T, Westergren A and Melgaard D. (2018). Associations between eating difficulties, nutritional status and activity of daily living in acute geriatric patients. Clin Nutr ESPEN, 1, 25, 95-9.

[12] Lahmann NA, Tannen A and Suhr R. (2016). Underweight and malnutrition in home care: A multicenter study. Clin Nutr, 1, 35(5), 1140-6.

[13] Tana C, Lauretani F, Ticinesi A, Gionti L, Nouvenne A, Prati B, et al. (2019). Impact of nutritional status on caregiver burden of elderly outpatients. A cross-sectional study. Nutrients, 11(2).

[14] Zhang Z, Pereira SL, Luo M and Matheson EM. (2017).Evaluation of blood biomarkers associated with risk of malnutrition in older adults: A systematic review and meta-analysis. Vol. 9, Nutrients. MDPI AG.

[15] Valmórbida JL, Goulart MR, Busnello FM and Pellanda LC. (20170.Nutritional knowledge and body mass index: A cross-sectional study. Rev Assoc Med Bras,n 63(9), 736-40.

[16] Craven DL, Lovell GP, Pelly FE and Isenring E. (2018). Community-Living Older Adults' Perceptions of Body Weight, Signs of Malnutrition and Sources of Information: a Descriptive Analysis of Survey Data. J Nutr Heal Aging, 1, 22(3), 393-9.

[17] Babiarczyk B and Turbiarz A. (2012). Body Mass Index in elderly people - do the reference ranges matter? Prog Heal Sci, 2(1)(July), 58-67.

[18] Ravasco P, Monteiro-Grillo I and Camilo ME. (2003). Does nutrition influence quality of life in cancer patients undergoing radiotherapy? Radiother Oncol [Internet], 67(2), 213-20. 
[19] Girón R, Matesanz C, García-Río F, De Santiago E, Mancha A, Rodríguez-Salvanés F, et al. (2009).Nutritional state during COPD exacerbation: Clinical and prognostic implications. Ann Nutr Metab, 54(1), 52-8.

[20] Damião R, Santos ÁDS, Matijasevich A and Menezes PR. (2017). Fatores associados ao risco de desnutrição em idosos do sudeste do Brasil. Rev Bras Epidemiol, 1, 20(4), 598-610.

[21] Batal M, Steinhouse L and Delisle H. (2019).The nutrition transition and the double burden of malnutrition. Med Sante Trop, 28(4), 345-50.

[22] Kang MC, Kim JH, Ryu SW, Moon JY, Park JH, Park JK, et al. (2018).Prevalence of malnutrition in hospitalized patients: A multicenter cross-sectional study. J Korean Med Sci., 1, 33(2).

[23] Wei JM, Li S, Claytor L, Partridge J and Goates S. (2018). Prevalence and predictors of malnutrition in elderly Chinese adults: Results from the China Health and Retirement Longitudinal Study. Public Health Nutr. 1, 21(17), 3129-34.

[24] Anderson MA. (2016).Caring for older adults holistically. $6^{\text {th }}$ ed. Philadelphia: F.A. Davis.

\section{How to cite this article}

Maturos Na Badalung K, Bosittipichet T and Leesri T. (2020). Nutritional status and associated factors among elderly people in primary care center. GSC Advanced Research and Reviews, 2(3), 28-35. 